\title{
Polifactory. Transforming Playful Movement into Sound: Co-create a Smart System for Children with Cerebral Palsy
}

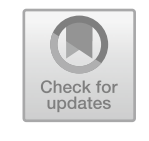

\author{
Carla Sedini, Laura Cipriani, Mirko Gelsomini, Stefano Maffei, \\ and Massimo Bianchini
}

This chapter explores the potential of co-creation and user innovation, investigating the physical-motor needs of children diagnosed with cerebral palsy with specific attention to the translation of movement in sound stimuli. It describes the co-design and development of BODYSOUND, a smart system that exploits a playful activity to encourage movements and transform them into sound.

\section{Introduction}

Polifactory (polifactory.polimi.it) is the makerspace and Fab Lab of Politecnico di Milano, created and coordinated by the Department of Design in collaboration with the Departments of Mechanical Engineering and Electronics, Information and Bioengineering. It is an interdisciplinary research lab and an Advanced Technology Centre that explores the relationship between design and new production models working in the fields of digital transformation, circular economy, open and user innovation.

C. Sedini $(\bowtie) \cdot$ L. Cipriani $\cdot$ M. Gelsomini $\cdot$ S. Maffei $\cdot$ M. Bianchini

Department of Design, Politecnico di Milano, Milan, Italy

e-mail: carla.sedini@polimi.it

L. Cipriani

e-mail: laura1.cipriani@polimi.it

M. Gelsomini

e-mail: mirko.gelsomini@polimi.it

S. Maffei

e-mail: stefano.maffei@polimi.it

M. Bianchini

e-mail: massimo.bianchini@polimi.it

(C) The Author(s) 2022 
Polifactory develops competitive and experimental research, consultancy projects for large companies and SMEs, experimental didactics, preincubation of talents and ideas for master degree students, $\mathrm{PhD}$ candidates, and fellow researchers.

Since 2017 Polifactory has begun to develop research processes aimed at studying the ecosystems of bottom-up and participatory innovation in the healthcare sector, such as MakeToCare research [3, 4], in collaboration with Sanofi Genzyme and Fondazione Politecnico, a systemic study of the actors and projects related to patient innovation in Italy.

To develop the SISCODE pilot project, the Polifactory team decided to consider the healthcare sector, with specific attention to the physical-motor needs of children diagnosed with cerebral palsy. Polifactory addressed its challenge with a service design approach. The final solution, called BODYSOUND, was co-created in collaboration with a wide range of stakeholders: patients (children), caregivers (parents), therapists, policymakers.

The journey was composed of three main phases, during which co-creation activities were carried out. After preliminary research and activities planning, the three main phases officially started in May 2019 and ended in November 2020.

The final solution is BODYSOUND, a system that proposes a new way of performing physical reactivation. It is based on choreutics (a combination of dance and music) and the transformation of movement into sound.

\section{Ecosystem, Context and Challenge Addressed}

Nowadays, healthcare systems worldwide have been incredibly stressed because of the pandemic. Several weaknesses have emerged and highlighted, in particular, the capacity to respond to emergencies as such in a systemic way, maintaining the provision of cures and support for other' typologies of illness and diseases. When Polifactory started its pilot project, which is the topic of this chapter, the pandemic was not diffused yet; however, the challenge and idea appeared lately to fit in this current situation.

Since 1997, Italy has opted for decentralising the healthcare system, giving regions more autonomy shifting towards a "public-private" model (privatisation boomed between 2010 and 2020). In 2014, Lombardy Region published the White Paper on developing the social and health system in Lombardy, followed by the law of reorganisation "Evolution of the Lombardy socio-economic system" (August 2015). In addition to that, Lombardy Region founded the Life Sciences Lombard Cluster, which collects all the public and private actors committed to diagnostics, advanced therapies, pharmaceuticals, medical devices, and technologies applied to health. The Cluster facilitates the progress of life sciences in Lombardy and creates new business opportunities among the members.

At the local level, the Municipality of Milan focuses on lines of action that are influent for Polifactory pilot project, such as urban manufacturing, start-ups, 
and knowledge-intensive economy with particular attention to technological and economic development, social cohesion, and participation in the city.

Although Italy ranked as the world's healthiest country and fourth in the health system efficiency rank [5], there has been a decreasing good health perception. The same happened for the trust in the medical system manifested by the Italian population.

In previous research activities, Polifactory carried out several interviews with doctors that confirm data on self-diagnosis; indeed, in many cases, patients, when they do not make the diagnosis and the cure by themselves, tend to adjust and correct the treatment without consulting the doctor first [2]. The habit of independently facing own small health problems is not necessarily bad. Experts speak of a process of "autonomy", which is well evaluated by operators in health policy because it reduces public spending and allows doctors to focus on the most serious pathologies. However, self-managed medicine is neither easy nor risk-free. Makerspaces and Fab Labs can operate as mediators and facilitators in processes of Patient Innovation $[1,6,11]$. In order to frame the concept of Patient Innovation it can be referred to the wider concept of Grassroots Innovation, defined as "a network of activists and organisations generating novel bottom-up solutions for sustainable development and sustainable consumption; solutions that respond to the local situation and the interests and values of the communities involved" [8]. The common characteristics which define a "low level" of Patient Innovation solutions can be summed up as follows. They are independent and personal because often developed to face individual issues; they are "redundant" because often the solution identified already existed; they are shared since often patients tend to share their positive experience with other people in their same condition. Makerspaces and Fab Labs can operate as mediators and facilitators in these processes to reach higher levels of Patient Innovation. Within this panorama, Italian and especially Milanese makerspaces and creative communities are particularly active in projects that deal with healthcare. Italian fablabs collaborate and operate on these issues together with patient associations, policymakers and RRI experts in several European projects, such as FabCare and MakeToCare (Polifactory); Made4You, Hackability Milano (OpenDot); OpenCare (WeMake); Ubora (Fab Lab Pisa), etc.

Looking at future policies, they would "enable or encourage more innovation effort investment by users at either the extensive (i.e. having more users engage in innovation or innovation diffusion) or intensive (i.e. enabling users that already innovate or diffuse innovations to invest greater efforts in doing so)" [9].

For these reasons, the challenge has been framed in the domain of healthcare and wellbeing. In particular, it was decided to focus on infantile Cerebral Palsy (CP), one of the most common physical disabilities in childhood: 2-2.5 per 1000 new borns and children are affected by CP (esteem of 3 per 1000 in Milan). Notwithstanding the diffusion of infantile CP, there is a lack of knowledge on it, and it is threatened as a rare disease: the public welfare system poorly sustains it, and informal caregivers (parents) are not supported or trained in managing their children' problems.

FightTheStroke was identified as the patients and caregivers association with whom to collaborate. It deals and operates with and for young stroke survivors with 
a disability of infantile CP and their families; it was crucial to know the issue better and contact families and therapists. Thanks to the dialogue with the president of the association and a survey carried out with parents of children affected with $\mathrm{CP}$, the final challenge of Polifactory was identified: addressing the physical-motor needs of children diagnosed with $\mathrm{CP}$, exploring them according to proprioception principles with specific attention to translating movement into sound stimuli.

\section{The Co-creation Journey}

Polifactory's co-creation journey was composed of the following stages, which were conducted recursively:

- analysis: survey and interviews

- ideation: co-design and experimentation workshops

- prototyping: three loops of development and tests.

Stakeholders involved are listed in Table 1, according to their participation in the different phases.

Thanks to the survey and the initial encounter with FightTheStroke, Polifactory reframed its challenge. It was decided to work on sports and play, focusing in particular on music because, as Rosenbaum and Gorter state [7], based on The International Classification of Functioning, Disability and Health (ICF) from the World Health Organisation, a true and effective global takeover of the child must give importance to a series of factors, described through six simple words, the so-called 6 F-Words: function, family, fitness, fun, friends, future [10].

Three co-design and experimental workshops were conducted during the ideation phase to validate some intuitions, refine the needs, and better identify the various stakeholder groups' effective problems. Thanks to the first cycle of workshops, needs and-subsequential-design opportunities were identified. Polifactory researchers refined and systematised the ideas that emerged during debrief moments, originating one singular idea: BODYSOUND.

The second cycle of workshops tried to verify it. The solution was presented to the participants, who imagined a user journey for it. In particular, they appreciated the systematisation of several ideas together, and they were able to discuss barriers and

Table 1 Project phases and stakeholder engagement

\begin{tabular}{l|l|l|l|l}
\hline & Patients & Caregivers & Therapists & Policymakers \\
\hline Analysis & & $\mathrm{X}$ & $\mathrm{X}$ & $\mathrm{X}$ \\
\hline Ideation 1st cycle & $\mathrm{X}$ & & & $\mathrm{X}$ \\
\hline Ideation 2nd cycle & $\mathrm{X}$ & & & $\mathrm{X}$ \\
\hline Ideation 3rd cycle & $\mathrm{X}$ & & & $\mathrm{X}$ \\
\hline Ideation 4th cycle & $\mathrm{X}$ & & & $\mathrm{X}$ \\
\hline
\end{tabular}


opportunities of the solution. From this second cycle emerged the concept of a virtual system where gamification elements help the motor stimulation and-possiblyreactivate the limbs. The result may occur by encouraging the children/users to use and move the plegic part by executing a series of choreographies.

The third cycle of workshops was organised after the first prototyping loop of the solution. Indeed, BODYSOUND prototyping followed a quick and dirt development approach, which is very useful for anticipating results and reviewing them during the early stages of work. Several versions ready to be tested were released, even if incompleted. The solution was refined according to tests feedback and co-design results. The last co-design workshop, which Polifactory conducted, was aimed at the design of BODYSOUND service. Both caregivers, therapists, and policymakers participated in this last workshop. The participants had to hypothesise the provider of the service, specific software functions and goals. Two primary "environments" (providers) were identified: schools and sports centers; however, the main idea did not change very much according to the various locations. As for the first co-design workshop, the debrief phase was crucial for identifying strengths and weaknesses and merging the most promising features into one unique idea.

The COVID-19 pandemic influenced BODYSOUND journey, and the core team had to review it according to the impossibility of being in the same place at the same time. In particular, Polifactory conducted the prototyping activities remotely, but to maintain the users' involvement, the team had to change the supporting technologies. It was decided to substitute the Kinect with an ordinary webcam to share BODYSOUND with the children who could test it (and use it) from their homes. Before starting this new testing phase, therapists, who participated in the journey, were invited to register the training gestures on a platform ad hoc developed. Polifactory did not abandon the original idea but decided to develop BODYSOUND web first, a more pervasive and accessible solution at the expense of accuracy, and then BODYSOUND pro.

\section{Experimentation: Output, Transformations, Outcomes}

BODYSOUND System proposes a new way of performing physical reactivation. It is based on choreutics (dance and music) through the transformation of movement into sound.

Within this system, children can perform a choreography and transform it into a melody. The system can detect the child's movement and collect information on his/her performances and improvements. Two types of solutions have been designed: BODYSOUND web and BODYSOUND pro.

\section{First solution-BODYSOUND web}

This solution (Fig. 1) is addressed to both patients and caregivers. It is developed for home training and can be used on any device with an internet connection equipped with a webcam (PC or tablet). It does not require installation but only the registration 


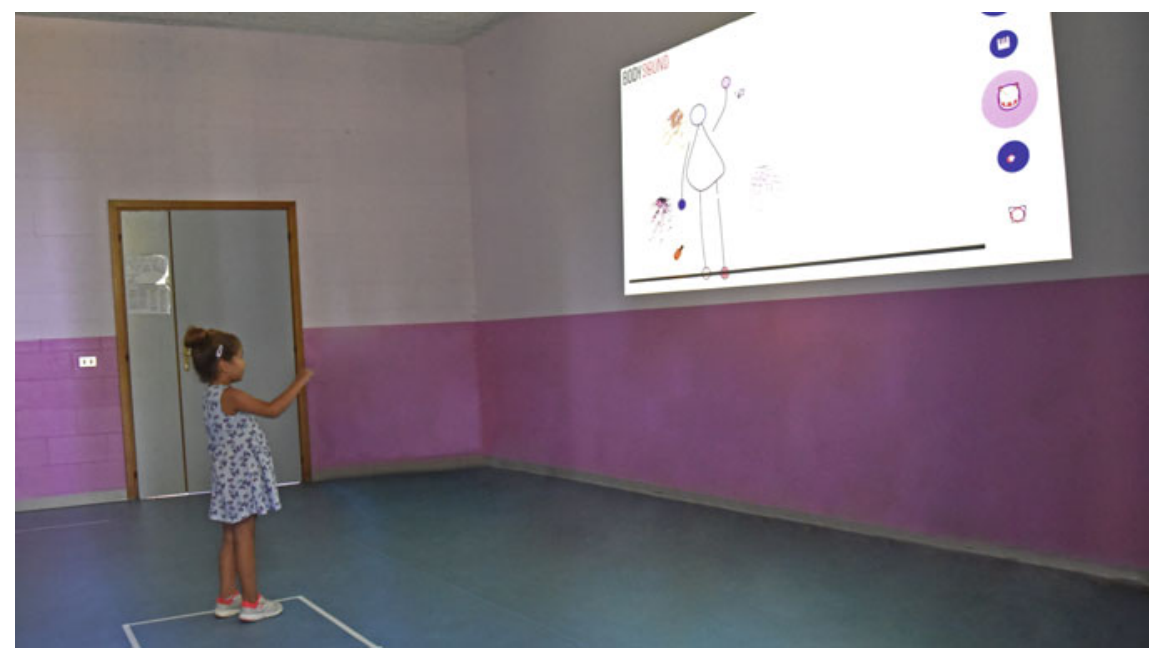

Fig. 1 Bodysound web, testing phase

of a user profile. This version is released with a finite number of exercises, which may vary due to the software updates.

\section{Second solution-BODYSOUND pro}

The solution (Fig. 2) is addressed to specialists in the medical, health, and sports field. It is tailored for training sessions to be carried out at schools or sport centers. The system integrates everything necessary (computer, Kinect, projector,...) to set up a space dedicated to the activity to make it accessible to more users simultaneously. This configuration allows the user to load custom movement sequences converted into exercise / game models.

Thanks to SISCODE experience, Polifactory improved its capacity to work in multidisciplinary teams and with an interdisciplinary approach since IT and sociology became part of the process. In addition to this, Polifactory acquired extended capacities to communicate and collaborate with various stakeholders. Furthermore, special attention has been dedicated to children as the main target. Polifactory had never worked with children before. It was a significant experience and opportunity for the team members to acquire competencies in engaging with specific groups of stakeholders.

Co-creation has already been closely linked to Politecnico's culture; however, thanks to SISCODE, Polifatory improved its application and deepened its knowledge of co-creation practices.

The introduction of this new knowledge also enlarged the stakeholder network of Polifactory, establishing new relationships and improving the existing ones with policymakers and patients associations. It opened up new possibilities and pathways towards the ideation and development of new experimentation research projects. 


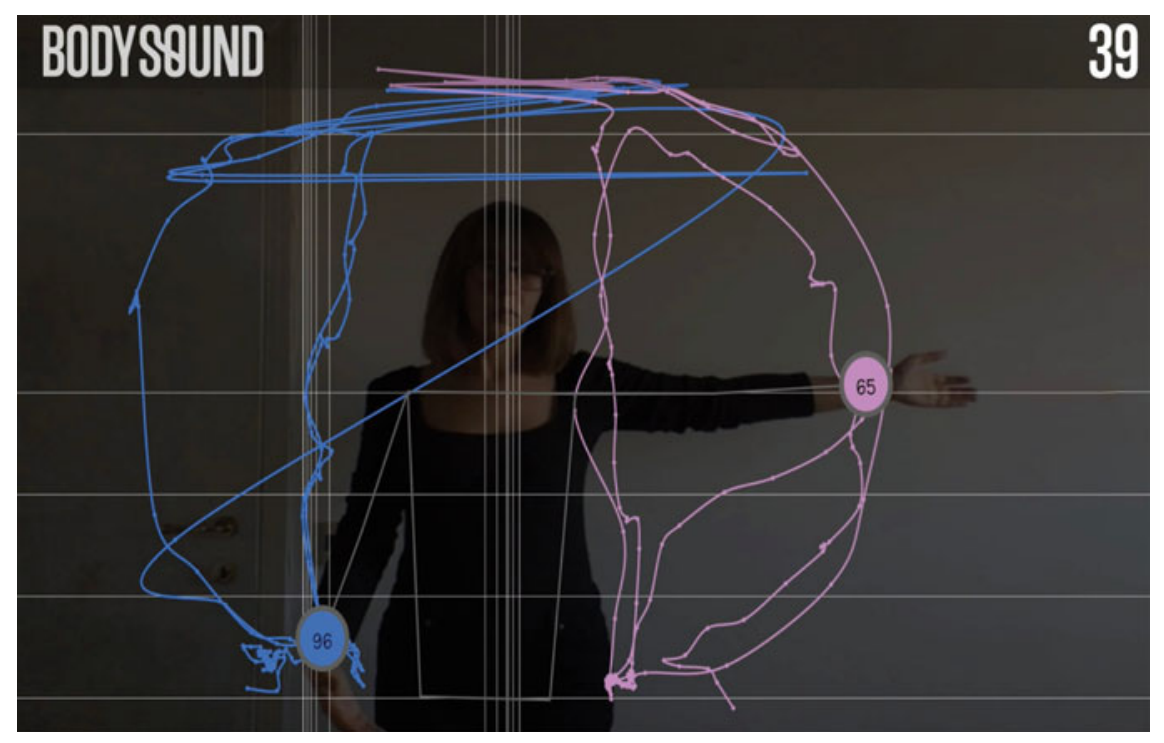

Fig. 2 Bodysound pro, testing phase

It is essential to look at small changes in the whole ecosystem, especially on the accumulative improvements that a pilot project such as BODYSOUND can have. In particular, stressing the relevance of co-creation in healthcare and wellbeing and the unique and crucial role that makerspace and Fab Labs can play in facilitating these processes. Some of the policymakers involved had never participated in activities like these before, providing several positive feedback. At the same time, the capacity of creating a "safe room" for users with specific needs, particularly vulnerable groups, to encounter other stakeholders like policymakers in leading positions was for sure a very relevant and trigger point. The COVID-19 situation stressed the importance of taking care of people with disabilities or in particular health conditions by distance, especially when it is impossible to attend rehabilitation and sports activities.

\section{Lessons Learnt and Reflections}

Thanks to the pilot project experience, Polifactory understood and verified that cocreation processes are highly dependent on the issues faced and their context. Codesigning with vulnerable users needs a different approach than more conventional users' co-creation processes.

The team decided to initially meet the stakeholders in dedicated and private moments because of the delicate and intimate issue and to organise lately a collective moment with all the stakeholders involved to build trust among all the participants. As researchers, the team identified the importance of the role of the mediator between 
different groups. However, additional mediators are crucial in facilitating the relationship between the research group and the main users. In the pilot project, the patient association had a relevant role in contacting and involving parents and children. Concerning building trust, it is essential to share knowledge from both sides, which means that —avoiding biases - researchers have to inform participants and keep them informed throughout the whole co-creation journey regardless of their rank or role outside of the project. Unfortunately, the COVID emergency diminished the possibility of having face-to-face moments of interaction identified as very relevant. Apart from participating in operative workshops, informal conversations were necessary to share opinions, build trust, and observe how interaction dynamics are performed. Therefore, the space of interaction is very relevant as well. Also, relaxing moments (such as lunches or coffee breaks) need to be organised and managed to facilitate exchanges and keep up the "safe space" created during the activities. Talking about the co-creation workshops is possible to say that they were all organised according to three main activities:

1. share information, knowledge, and experiences

2. hands and minds on: imagine possible scenarios and solutions through the use of co-design tools

3. reflect (and share again): collectively analyse the solution identified and select the best ones.

Finally, respect is one of the most relevant factors to consider: stakeholders have their commitments, and time is one of the most precious resources. Thus, it is crucial to give value to the time they donate.

To sum up, Polifactory identified four main elements characterising a co-creation journey:

- it is an accumulative and iterative process

- it needs to pay attention to time and space issues

- it requires the researcher to be a mediator

- it has to keep stakeholders informed throughout the whole process.

\section{References}

1. DeMonaco H, Oliveira P, Torrance A, von Hippel C, von Hippel E (2019) When patients become innovators. MIT Sloan Manag Rev. https://sloanreview.mit.edu/article/when-patientsbecome-innovators/. Last accessed 2021/03/28

2. Eurispes: Rapporto Italia 2017 (2017)

3. Maffei S, Bianchini M, Parini B, Delli Zotti E (2017) MakeToCare. An ecosystem of actors and user-centered innovation for the innovation in the field of healthcare. Libraccio Editore, Milano

4. Maffei S, Bianchini M, Parini B, Cipriani L (2019) MakeToCare2. La patient innovation in Italia tra progetto e mercato. Libraccio Editore, Milano 
5. Miller LJ, Lu W (2018) These are the economies with the most (and least) efficient health care. Available at https://www.bloomberg.com/news/articles/2018-09-19/u-s-near-bottom-ofhealth-index-hong-kong-and-singapore-at-top. Last accessed 2021/03/28

6. Oliveira P, Zejnilovic L, Canhão H, von Hippel E (2014) Patient innovation under rare diseases and chronic needs. Orphanet J Rare Dis 9(1):850

7. Rosenbaum P, Gorter JW (2012) The 'F-words' in childhood disability: I swear this is how we should think! Child: Care, Health Dev 38(4):457-463

8. Seyfang G, Smith A (2007) Grassroots innovations for sustainable development: towards a new research and policy agenda. Environ Polit 16(4):584-603

9. Svensson PO, Hartmann RK (2018) Policies to promote user innovation: Makerspaces and clinician innovation in Swedish hospitals. Res Policy 47(1):277-288

10. WHO (2001) World Health Organisation international classification of functioning. Disability and Health, Geneva

11. Zejnilovic L, Oliveira P, Canhão H (2016) Innovations by and for patients, and their place in the future health care system. In: Pinkwart A, Meffert H, Albach H, Reichwald R, von Eiff E (eds) Boundaryless hospital: rethink and redefine health care management. Springer, Berlin

Open Access This chapter is licensed under the terms of the Creative Commons Attribution 4.0 International License (http://creativecommons.org/licenses/by/4.0/), which permits use, sharing, adaptation, distribution and reproduction in any medium or format, as long as you give appropriate credit to the original author(s) and the source, provide a link to the Creative Commons license and indicate if changes were made.

The images or other third party material in this chapter are included in the chapter's Creative Commons license, unless indicated otherwise in a credit line to the material. If material is not included in the chapter's Creative Commons license and your intended use is not permitted by statutory regulation or exceeds the permitted use, you will need to obtain permission directly from the copyright holder.

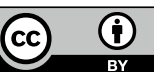

